Jurnal Ekonomi Modernisasi

http:// ejournal.unikama.ac.id/index.php/JEKO

JEM 13 (1) 2017, 46-52

\title{
Strategi Pertumbuhan Usaha Kecil Menengah (UKM)
}

\author{
Endi Sarwoko \\ Universitas Kanjuruhan Malang
}

\begin{abstract}
This study aims to analyze the strategies needed for SMEs to improve business performance. Research conducted on the owners of SMEs in Malang Regency as many as 50 SMEs. Data collection techniques used questionnaires, and data analysis using Confirmatory Factor Analysis. The results showed that the implementation of small and medium enterprise business growth strategy includes penetration strategy, market development, product development, and diversification strategy. A penetration strategy is a factor that plays a major role in improving the growth strategy. Another finding is that product development strategy is a strategy preferred by small and medium business owners by generating products or services with different characteristics from competitors, and utilizing technology to make production processes more efficient. A penetration strategy is the most important type of strategy for SME growth, but it is the most widely applied product development strategy. The implication of this research is that SMEs should begin to improve the implementation of penetration strategies to improve business performance by attracting old customers to buy more SME products.
\end{abstract}

Keywords: Business Growth Strategy ;SMEs

\section{Abstrak}

Penelitian ini bertujuan untuk menganalisis strategi diperlukan UKM untuk meningkatkan kinerja usaha. Penelitian dilakukan terhadap pemilik UKM di Kabupaten Malang sebanyak 50 UKM. Teknik pengumpulan data menggunakan angket, dan analisis data menggunakan Analisis Faktor Konfirmatori. Hasil penelitian menunjukkan bahwa pelaksanaan strategi pertumbuhan usaha usaha kecil menengah meliputi strategi penetrasi, pengembangan pasar, pengembangan produk, dan strategi diversifikasi. Strategi penetrasi merupakan faktor yang berperan paling besar meningkatkan strategi pertumbuhan. Temuan lain adalah bahwa strategi pengembangan produk merupakan strategi yang lebih banyak dipilih oleh para pemilik usaha kecil menengah dengan cara menghasilkan produk atau jasa dengan ciri-ciri yang berbeda dari pesaing, dan memanfaatkan teknologi agar proses produksi lebih efisien. Strategi penetrasi merupakan jenis strategi yang paling penting bagi pertumbuhan UKM, namun justru strategi pengembangan produk yang paling banyak diterapkan. Implikasi penelitian ini bahwa UKM harus mulai meningkatkan implementasi strategi penetrasi agar mampu meningkatkan kinerja usaha, dengan cara menjaring para pelanggan lama untuk membeli lebih banyak produk UKM.

Kata kunci: Strategi Pertumbuhan Usaha ; UKM

Permalink/DOI : http://dx.doi.org/10.21067/jem.v13i1.1745

Cara mengutip $\quad$ : Sarwoko, E. (2017). Strategi Pertumbuhan Usaha Kecil Menengah (UKM). Jurnal Ekonomi Modernisasi, 13(1), 46-52. doi:http://dx.doi.org/10.21067/jem.v13i1.1764

Sejarah Artikel : : Artikel diterima : Desember 2016; direvisi Januari 2017; diterima Februari 2017

\footnotetext{
Alamat korespondensi :

Fakultas Ekonomika dan Bisnis, Universitas Kanjuruhan Malanng

Jl. S. Supriyadi No. 48 Malang, Jawa Timur

E-mail: endiswk@unikama.ac.id 


\section{Pendahuluan}

Publikasi Dinas Koperasi dan UMKM Jawa Timur, dari sejumlah 1.671 UKM binaan unggulan, hanya $20 \%$ yang sudah mampu memasarkan produk pada pasar ekspor. Sementara untuk wilayah Malang Raya (Kota Malang, Kabupaten Malang, dan Kota Batu) dari sejumlah 160 UKM unggulan, hanya 53 usaha saja yang mampu menembus pasar ekspor Hal ini menunjukkan bahwa pertumbuhan UKM di satu sisi dapat menjadi tulang punggung perekonomian, karena mampu menyerap tenaga kerja serta mampu memberikan kontribusi terhadap pembentukan Produk Domestik Bruto Kabupaten Malang, namun di sisi lain hanya sebanyak 27 unit usaha atau 0,031\% yang telah menembus pasar ekspor, dan $0,026 \%$ UKM telah memiliki produk unggulan. Kondisi ini menunjukkan bahwa tingkat keberhasilan usaha kecil menengah masih rendah, sehingga perlu diketahui berbagai faktor penentu keberhasilan pertumbuhan UKM.

Studi tentang faktor yang mempengaruhi keberhasilan usaha kecil dapat dikelompokkan menjadi dua yaitu faktor eksternal dan faktor internal. Faktor eksternal mencakup peran pemerintah dalam menciptakan lingkungan yang kondusif bagi pertumbuhan usaha kecil, sedangkan faktor internal yang menentukan kesuksesan usaha adalah variabel individu meliputi karakteristik pengusaha/pemilik dan kompetensi kewirausahaan (Sarwoko, 2013). Variabel individu yang mempengaruhi keberhasilan usaha kecil menengah juga bisa dilihat dari orientasi kewirausahaan (entrepreneurial orientation) (Lumpkin \& Dess, 2001; Wiklund \& Shepherd, 2005;), nilai-nilai individu (personal value), ciri-ciri kepribadian (personality trait) (Blackman, 2003; Verheul et al., 2002;
Boohene et al., 2008); pengalaman pemilik/manajer (Lee and Tsang, 2001).

Keberhasilan usaha kecil terbukti ditentukan oleh karakteristik dan kompetensi wirausaha, namun jika lingkungan usaha semakin dinamis dan persaingan yang semakin meningkat maka keberhasilan usaha tidak terlepas dari peran strategi. Li et al. (2009) menyatakan bahwa kinerja usaha berhubungan dengan strategi kewirausahaan.

Strategi kewirausahaan akan membantu pertumbuhan perusahaan karena dapat memanfaatkan peluang yang ada (Covin \& Slevin, 1991; Zahra \& Covin, 1995). Beberapa penelitian tersebut telah menemukan bahwa strategi sebagai faktor penentu kinerja usaha, tetapi penelitian lain membuktikan strategi tidak berpengaruh secara langsung terhadap kinerja bisnis (Gibcus dan Kemp, 2003; Kemp dan Verhoeven, 2002). Covin dan Slevin (1989) tidak menemukan hubungan langsung antara strategi kewirausahaan dan kinerja usaha kecil. Chen et al. (2006) yang meneliti strategi kewirausahaan di Taiwan menemukan bahwa strategi kewirausahaan dapat memiliki efek yang berbeda terhadap kinerja usaha. Hashim (2000) menyatakan bahwa kinerja usaha kecil menengah bervariasi dalam menentukan pilihan strategi bisnis yang diadopsi. Penelitian ini dilakukan dengan tujuan untuk mengetahui strategi apa saja yang diperlukan oleh UKM untuk menjamin tercapainya kinerja bisnis.

\section{Tinjauan Pustaka}

\section{Strategi Pertumbuhan Usaha}

Kinerja perusahaan-perusahaan kecil terbukti ditentukan strategi yang mereka gunakan, kemampuan untuk merumuskan dan menerapkan strategi yang tepat sesuai dengan lingkungan usaha akan menentukan 
keberhasilan atau kegagalan usaha kecil (Covin dan Slevin, 1989). Rue dan Ibrahim (1998) menyatakan strategi berhubungan dengan kinerja perusahaan.

Literatur usaha kecil menyajikan jenis strategi berbentuk kontinum mulai dari konservatif sampai proaktif-reaktif (Covin dan Slevin, 1989). Perusahaan yang proaktif menginvestasikan waktu dalam mengembangkan strategi akan mencapai kinerja yang lebih tinggi dibandingkan perusahaan yang kurang proaktif dan tidak mengembangkan strategi (Covin dan Covin, 1990).

Strategi kewirausahaan (entrepreneurial strategy) merupakan sejumlah keputusan, tindakan, dan reaksi menciptakan, kemudian mengeksploitasi sebuah usaha dengan cara memaksimalkan manfaat dari kebaruan serta meminimalkan (Hisrich et al., 2008). Strategi kewirausahaan dibedakan menjadi 2 yaitu strategi usaha baru dan strategi pertumbuhan. Strategi pertumbuhan meliputi: (1). Penetration Strategy, yaitu strategi yang membuat para konsumen lama untuk bersedia membeli produk lebih banyak dari perusahaan. Strategi ini berfokus pada produk perusahaan pada pasar yang sudah ada., (2). Market Development Strategy, yaitu strategi dengan cara menjual produk yang sudah ada pada ke konsumen yang baru. Meliputi penjualan produk perusahaan yang sudah ada pada kelompok konsumen yang baru. (3). Product Development Strategy, yaitu strategi dengan cara mengembangkan dan menjual produk-produk baru kepada pelanggan perusahaan. (4). Diversification Strategy yaitu strategi yang dilakukan dengan cara menjual produk baru ke pasar yang baru. Strategi diversifikasi berkaitan dengan pengetahuan dari pengusaha dan perusahaan.

Gibcus dan Kemp (2003) meneliti tentang strategy and small firm performance di Netherlands. Tujuan penelitian adalah untuk memberikan berkontribusi tentang hubungan antara strategi dan kinerja usaha kecil menengah. Penelitian Gibcus and Kemp (2002) memiliki hasil berbeda dari penelitian-penelitian sebelumnya, yang dinyatakan bahwa pilihan strategi tidak berpengaruh terhadap kinerja usaha kecil menengah. Terdapat perbedaan strategi di antara kelompok kinerja usaha kecil menengah. Namun, strategi yang dipilih tidak mempengaruhi kinerja kinerja usaha kecil menengah. Hasil penelitian menunjukkan adanya hubungan langsung yang lemah dan tidak signifikan antara strategi dengan kinerja perusahaan (Li et al., 2005). Kinerja usaha berhubungan dengan strategi kewirausahaan, apabila dimoderasi oleh faktor lingkungan dan kompetensi perusahaan. Penelitian Hashim (2000) menemukan bahwa kinerja usaha kecil menengah di Malaysia bervariasi tergantung perbedaan pilihan strategi bisnis yang digunakan.

\section{Metode}

Berdasarkan tujuan yang ingin dicapai, maka penelitian ini termasuk dalam kategori penelitian eksplanatori (explanatory research), yaitu penelitian yang dilakukan dengan cara mengidentifikasikan fakta dan peristiwa yang muncul dari obyek yang diteliti, dan selanjutnya melakukan penyelidikan untuk menjelaskan fenomena permasalahan yang didasarkan pada variabel yang diteliti.

Penelitian dilakukan pada UKM Binaan Dinas Koperasi dan UKM Kabupaten Malang yang berjumlah 232 unit usaha. Sampel penelitian diambil dengan teknik purposive sampling yaitu sampel berdasarkan kriteria UKM yang berskala ekspor dan memiliki produk unggulan, sehingga terpilih sebanyak 50 pemilik/pengusaha. Pertimbangan hanya 50 
UKM sebagai sampel penelitian karena merupakan UKM unggulan dan binaan Dinas Koperasi dan UKM Kabupaten Malang, sehingga dapat diketahui faktorfaktor strategi yang mempengaruhi keberhasilan mereka.

Penelitian menggunakan sumber data primer diperoleh dengan cara menyebarkan angket kepada para pemilik/wirausaha. Kuesioner yang digunakan dirancang dalam bentuk kuesioner tertutup dengan Skala Likert, digunakan untuk mengukur indikator strategi pertumbuhan usaha. Kuesioner yang digunakan dilakukan uji validitas dan reliabilitas instrumen, dimana hasil uji coba menunjukkan bahwa kuesioner yang digunakan telah memiliki validitas dan reliabilitas instrumen, ditunjukkan nilai corrected item total correlation masing-masing butir pertanyaan di atas 0,361 dan nilai $A \not p h a$ Cronbach adalah sebesar 0,86.

Strategi pertumbuhan merupakan pelaksanaan strategi pertumbuhan dari pemilik UKM. Pengukuran variabel strategi dalam penelitian ini menggunakan indikator yang diambil dari Hisrich et al. (2008) yang terdiri dari:
a. Penetrasi
b. Pengembangan pasar
c. Pengembangan produk
d. Diversifikasi

Teknik analisis data menggunakan Analisis Faktor Konfirmatory (ConfirmatoryFactor Analysis). Analisis faktor konfirmatori digunakan untuk menentukan strategi yang tepat dan memberikan kontribusi terhadap pertumbuhan UKM, selain itu, penelitian ini juga untuk mengidentifikasi faktor yang mempunyai kontribusi paling besar terhadap pertumbuhan UKM.

\section{Hasil dan Pembahasan}

Hasil analisis deskriptif yang disajikan pada tabel 1. diperoleh temuan bahwa strategi pengembangan produk merupakan strategi yang lebih banyak dipilih oleh para pemilik usaha kecil menengah di Kabupaten Malang, hal ini ditunjukkan bahwa strategi pengembangan produk memiliki nilai rata-rata (mean) terbesar yaitu 4,15 dibandingkan strategi yang lain. Strategi pengembangan produk yang dilakukan para pemilik/pengusaha dengan cara menghasilkan produk atau jasa dengan ciriciri yang berbeda dari pesaing, serta memanfaatkan teknologi agar proses produksi lebih efisien. Sedangkan strategi yang paling rendah penerapannya oleh para pemilik/pengusaha UKM di Kabupaten Malang adalah strategi penetrasi dengan nilai rata-rata 3,28.

Tabel 1. Statistik Deskriptif

\begin{tabular}{|c|c|c|c|c|c|}
\hline & $\mathrm{N}$ & Minimum & Maximum & Mean & $\begin{array}{c}\text { Std. } \\
\text { Deviation }\end{array}$ \\
\hline Penetrasi & 50 & 2.00 & 5.00 & 3.2800 & .60744 \\
\hline Pengembangan Pasar & 50 & 2.00 & 5.00 & 3.1800 & .69076 \\
\hline Pengembangan Produk & 50 & 3.00 & 5.00 & 4.1500 & .62474 \\
\hline Diversifikasi & 50 & 3.00 & 5.00 & 3.9900 & .55778 \\
\hline
\end{tabular}

Sumber: Hasil Analisis, Data diolah 2016 
Hasil analisis faktor yang disajikan pada tabel 2. bahwa pelaksanaan strategi pertumbuhan usaha pada usaha kecil menengah meliputi penetrasi, pengembangan pasar, pengembangan produk, dan diversifikasi. Hal ini dapat diketahui berdasarkan yaitu dari nilai Estimate Standardized Regression Weight bahwa keempat strategi memiliki nilai di atas 0,5 sebagaimana disajikan pada tabel berikut:

Tabel 2. Standardized Regression Weights

\begin{tabular}{lrrr}
\hline & Estimate & S.E. & C.R. \\
\hline Diversifikasi & .750 & & \\
Pengembangan produk & .684 & .231 & 4.425 \\
Pengembangan pasar & .756 & .257 & 4.856 \\
Penetrasi & .808 & .230 & 5.092 \\
\hline
\end{tabular}

Sumber: Hasil analisis, diolah 2016.

walaupun berdasarkan hasil analisis strategi

Berdasarkan hasil analisis dapat diketahui bahwa strategi penetrasi merupakan strategi yang paling besar kontribusinya dalam pelaksanaan strategi pertumbuhan usaha kecil menengah, ditunjukkan nilai loading factor terbesar yaitu 8,08 selanjutnya strategi yang paling rendah kontribusinya dalam pelaksanaan strategi adalah pengembangan produk.

Berdasarkan hasil analisis deskriptif dan analisis faktor konformatory dapat dikemukakan 2 hal yaitu: Strategi penetrasi merupakan jenis strategi yang paling rendah diimplementasikan dalam pertumbuhan UKM di Kabupaten Malang, padahal strategi penetrasi ternyata memberikan kontribusi paling besar di antara strategi yang lain dalam pertumbuhan UKM di Kabupaten Malang. Kelemahan para pemilik/pengusaha UKM di Kabupaten Malang dalam mengimplementasikan strategi penetrasi disebabkan ketidakmampuan para pengusaha mendorong para konsumen lama untuk membeli produk lebih banyak produk perusahaan. Strategi pengembangan produk merupakan strategi yang paling banyak diterapkan oleh para pengusaha UKM, pengembangan produk memberikan

kontribusi paling rendah dalam pertumbuhan UKM di Kabupaten Malang. Berdasarkan dua kondisi tersebut dapat dinyatakan bahwa bahwa keunggulan dari UKM di Kabupaten Malang adalah dalam hal kemampuan mengembangkan produk, namun kurang didukung dengan kemampuan untuk mengimplementasikan strategi penetrasi, hal inilah yang menjadi faktor penghambat pertumbuhan UKM di Kabupaten Malang, yaitu kurang tepatnya implementasi strategi pertumbuhan yang dipilih guna mencapai kinerja bisnis. Oleh karena itu untuk mencapai pertumbuhan atau kinerja UKM binaan di Kabupaten Malang, maka para pemilik/pengusaha harus mulai berani mengimplementasikan strategi penetrasi dengan menetapkan strategi mendorong para konsumen lama untuk membeli produk lebih banyak produk perusahaan, upaya promosi tentu tidak dapat dihindari untuk mengingatkan para pelanggan terhadap keberadaan produk dari UKM. 
Endi Sarwoko / Strategi Pertumbuhan Usaha Kecil Menengah ....

\section{Simpulan}

Strategi penetrasi merupakan strategi yang paling besar perannya dalam pelaksanaan strategi pertumbuhan usaha kecil menengah. Temuan lain dari penelitian adalah bahwa ternyata strategi pengembangan produk merupakan strategi yang lebih banyak dipilih oleh para pemilik usaha kecil menengah di Kabupaten Malang dengan cara menghasilkan produk atau jasa dengan ciri-ciri yang berbeda dari pesaing, serta memanfaatkan teknologi agar proses produksi lebih efisien. Jadi walaupun strategi penetrasi merupakan jenis strategi yang paling penting bagi pertumbuhan UKM, tetapi justru strategi pengembangan produk yang paling banyak diterapkan. Faktor inilah yang menjadi faktor penghambat pertumbuhan UKM di Kabupaten Malang. Oleh karena itu para pemilik UKM harus mulai meningkatkan implementasi strategi penetrasi agar mampu meningkatkan kinerja usaha. Strategi penetrasi merupakan strategi yang dilakukan oleh UKM agar para konsumen lama bersedia untuk membeli lebih banyak produk.

\section{Daftar Pustaka}

Blackman, A. J. (2003). Entrepreneurs: Interrelationships between their characteristics, values, expectations, management practices and SME performance. Griffith Univercity, 231. (Submitted in fulfilment of the requirements of the degree of Doctor of Philosophy)

Boohene, R., Sheridan, A., \& Kotey, B. (2008). Gender, personal values, strategies and small business performance: A Ghanaian case study. Equal Opportunities International, 27(3), 237-257. http://doi.org/10.1108/02610150810 $\underline{860075}$

Chen, G., Li, J., \& Matlay, H. (2006). Who are the Chinese private entrepreneurs?: A study of entrepreneurial attributes and business governance. Journal of Small Business and Enterprise Development, 13(2), 148-160.

http://doi.org/10.1108/146260006106 $\underline{65863}$

Covin, J. G., \& Slevin, D. P. (1989). Strategic Management of Small Firms in Hostile and Benign Environments. Strategic Management Journal, 10(1), 75-87. http://doi.org/10.1002/smj.42501001 $\underline{07}$

Covin, J.G., \& Covin, T. (1990). Competitive aggressiveness, environmental context, and small firm performance. Entrepreneurship: Theory and Practice, 14(4), 35-50.

Gibcus, P. \& Kemp, R. (2003). Strategy and small firm performance, Research Report H200208, January, EIM, Zoetermeer.

Hashim, M. K. (2000). Business strategy and performance in Malaysian SMEs: A recent survey. Malaysian Management Review, 35(2), 1-10.

Hisrich, R.D., Peter, M.P., and Shepherd, D.A., (2008). Entrepreneurship. Chriswan Sungkono dan Diana Angelica (penerjemah), Kewirausahaan, Salemba Empat, Jakarta.

Kemp, R.G.M., \& Verhoeven, W.H.J. (2002). Growth patterns of medium-sized, fastgrowing firms: the optimal resource bundles for organisational growth and performance, EIM SCALES Research Report H200111, EIM, Zoetermeer 
Li, H., Zhang, Y., \& Chan, T. S. (2005). Entrepreneurial strategy making and performance in China's new technology ventures - The contingency effect of environments and firm competences. Journal of High Technology Management Research, 16(1), 37-57. http://doi.org/10.1016/j.hitech.2005.0 $\underline{6.003}$

Li, Y.-H., Huang, J.-W., \& Tsai, M.-T. (2009). Entrepreneurial orientation and firm performance: The role of knowledge creation process. Industrial Marketing Management, 38(4), 440-449. http://doi.org/10.1016/j.indmarman.2 $\underline{008.02 .004}$

Lumpkin, G. T., \& Dess, G. G. (2001). Linking two dimensions of entrepreneurial orientation to firm performance: The moderating role of environment and industry life cycle. Journal of Business Venturing, 16(5), 429451. http://doi.org/10.1016/S0883$\underline{9026(00) 00048-3}$

Rue, L.W. and Ibrahim, N.A. (1998), The relationship between planning sophistication and performance in small businesses, Journal of Small Business Management, 36(4), 24-32.

Sarwoko, E., \& Hadiwidjojo, D. (2013). Entrepreneurial Characteristics and Competency as Determinants of Business Performance in SMEs. IOSR Journal of Business and Management (IOSRJBM), 7(3), 31-38. http://doi.org/10.9790/487X$\underline{0733138}$

Verheul, I., Uhlaner, L. and Thurik, A.R. (2002), "What is an entrepreneur? Self-image, activities and gender", Proceedings of the International Council for Small Business, 47th World Conference, San Juan, 16-19 June.
Wiklund, J. \& Shepherd, D. (2005), Entrepreneurial orientation and small business performance: a configurational approach, Journal of Business Venturing, 20 (1): 71-91. http://dx.doi.org/10.1016/j.jbusvent.2 $\underline{004.01 .001 .}$.

Zahra, S.A, and Covin, J.G. (1995). Contextual influences on the corporate entrepreneurship performance relationship: Alongitudinal analysis. Journal of Business Venturing 10(1), 43-58. http://dx.doi.org/10.1016/08839026(94)00004-E. 